\title{
OPTIMIZATION OF MICRO AIR VEHICLE AIRFOIL
}

\author{
N.S.K.Teja ${ }^{1}$, AVRK Teja ${ }^{2}$, J.Sri Harsha ${ }^{3}$, S.Ganesh ${ }^{4}$, K.V.Ramana ${ }^{5}$ \\ ${ }^{1,2,3,4}$ Final Year Students Department of Mechanical Engineering, $K$ L University-522502 \\ ${ }^{5}$ Professor, Department of Mechanical Engineering, $K$ L University-522502 \\ skt041@gmail.com
}

\begin{abstract}
Micro Air Vehicles (MAVs) are small and undetectable, with a wing span of around 150mm and weighs 200 grams. Over the past decade, MAVs are gaining importance in research due to their unique capability. They are untraceable by humans at $100 \mathrm{~m}$ above the ground level. In MAVs airfoils play a major role to maximize the lift and minimize the drag forces. In the present work two airfoils of different configuration have been selected. Modeling has been done using solid works, by plotting coordinates of the airfoils specified by NACA. For both the configurations of airfoils Polyethylene Terephthalate material was selected due to its light weight and impact resistant properties. Static and dynamic analysis has been taken up to investigate the behavior of selected configurations. At the end, most optimum shape of airfoil is suggested.
\end{abstract}

Key Words: Micro Air Vehicle, Airfoil, NACA, Reynolds Number.

\section{INTRODUCTION}

Micro aerial vehicles are very small, having the aspect ratio of 1 to 1.5 , and operate at relatively low Reynolds Numbers [1]. There are three types of MAVs. They are fixed wing, flapping wing and rotary wing. Over the past decade, MAVs have received an increasing amount of attention due to their unique capabilities in missions such as covert imaging, biological and chemical agent detection, battlefield surveillance, traffic monitoring and urban intelligence gathering. MAVs generally fly in the Reynolds number $\left(\mathrm{R}_{\mathrm{e}} \mathrm{N}_{\mathrm{o}}\right.$ ) range of 1000 to 120000 . Their performance is poor at low $\mathrm{R}_{\mathrm{e}} \mathrm{N}_{\mathrm{o}} \mathrm{s}$ due to induced losses. A good airfoil choice for MAVs will try to accomplish several goals such as to delay the onset of the laminar separation and therefore flow separation, to achieve a maximum lift coefficient and to keep induced as well as profile drag at a minimum. The theoretical investigation carried out in this study has emphasized the design optimization of fixed wing of Micro Air Vehicle. Several areas need to be carefully considered for the selection of a practical airfoil, including aerodynamics. The salient features of using MAVs have resulted in the establishment of some researches towards the optimization and enhancement of airfoils [2]. The first comprehensive research on MAV was conducted in 1993 by RAND institution. [3,4].

\section{SELECTION}

Airfoils for MAV which hovers at a height of $100 \mathrm{~m}$ from the ground are selected for a Reynolds Number of 45000 . For the selected height and stipulated Reynolds Number R140 and E203 as shown in Figs 1 and 2 have been selected for investigation. Other test conditions are

\footnotetext{
Density of air $=1.225 \mathrm{Kg} / \mathrm{m}^{3}$

Velocity of air $=15 \mathrm{~m} / \mathrm{s}$

Pressure $\quad=1 \mathrm{~atm}$
}

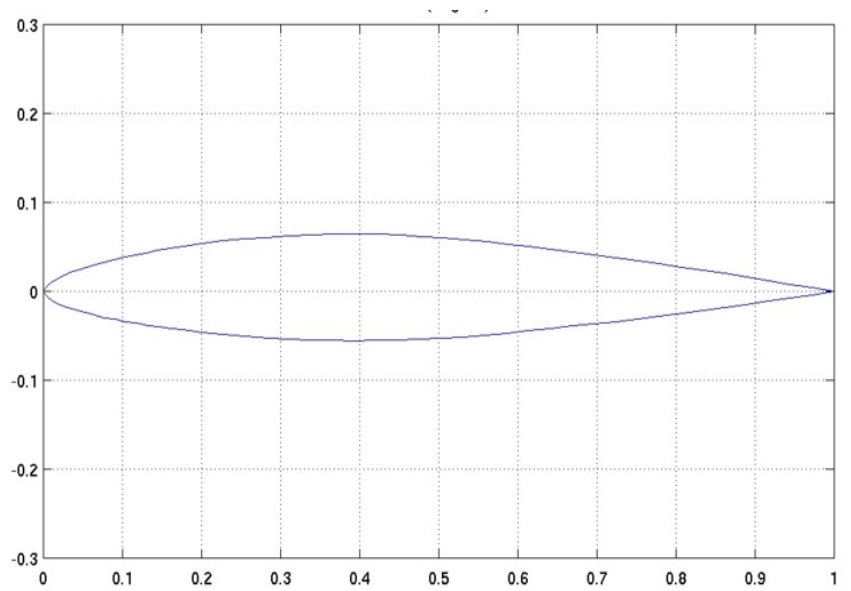

Fig-1: Airfoil Of R140

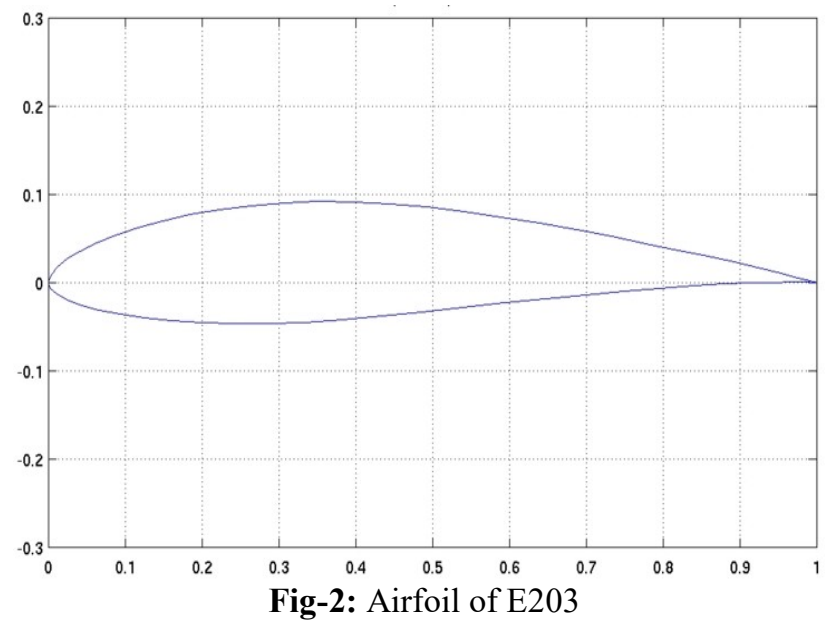

3. MODELING

The coordinates for the selected airfoils have been obtained from NACA. The chord lengths for MAV are $125 \mathrm{~mm}$ at the root and $100 \mathrm{~mm}$ at the tip. Coordinates for chord length of 
$125 \times 100 \mathrm{~mm}$ have been established. The airfoils are modeled in SOLID WORKS and drawn using curve through coordinates option. Loft command is used to model the airfoil as a solid object as shown in Fig.3.

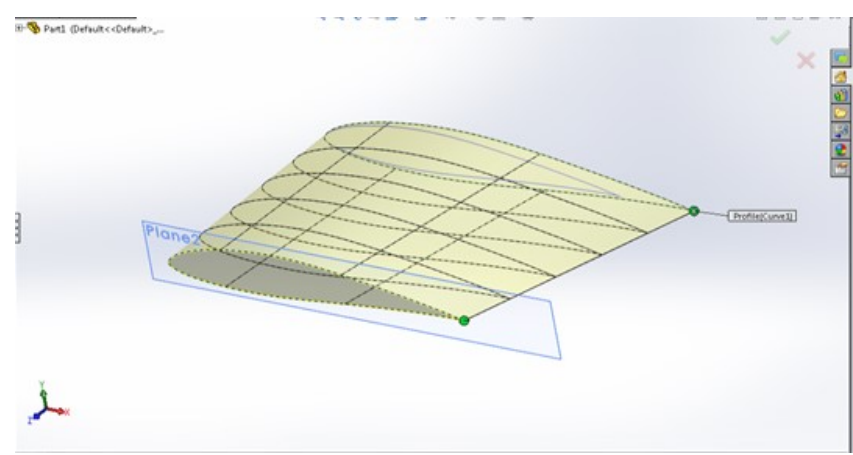

Fig-3: Modeling using loft command

\section{MESHING}

Volume Tetra element is selected and meshing of the airfoil as shown in Fig.4 and subsequently surface meshing is verified using mask command, as shown in Fig.5.

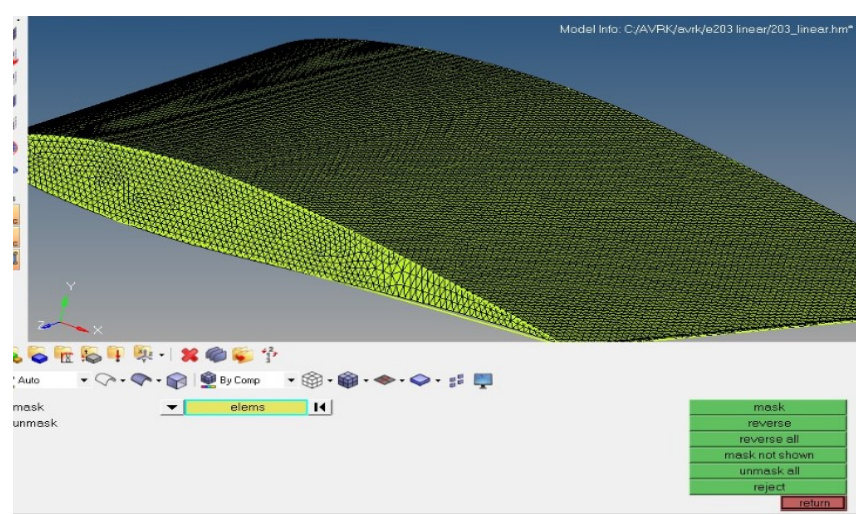

Fig-4: Volume tetra mesh

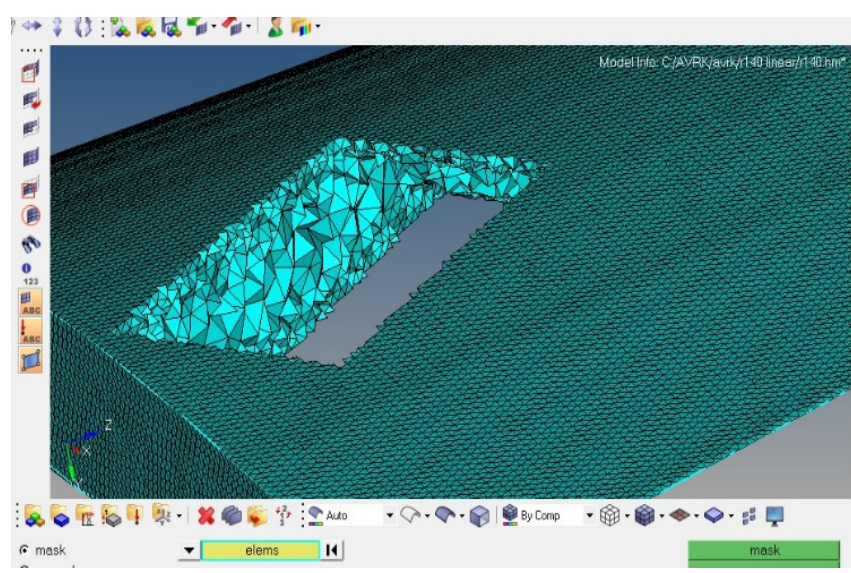

Fig-5: Mask image

\section{Load Calculation}

The load on the airfoil is the combination of lift and drag. For the analysis only lift force is considered as it deviates the drag force and which will be perpendicular to the cross section of airfoil. The lift load is obtained using Kutta Joukowski equation, as given below.
$\mathrm{F}=(\rho * \mathrm{~V} * \mathrm{~L} * \Gamma)$

Where $F=$ Force, $\rho=$ Density, $V=$ Velocity, $L=$ Span, $\Gamma=$ Circulation.

\section{ANALYSIS}

For the static and dynamic analysis, the calculated load is applied uniformly over all the nodes, by fixing an end of the airfoil.

\section{RESULTS}

Maximum stress and displacement of E203 are shown in Fig.6 and Fig.7 and natural frequencies are presented in Table.1.

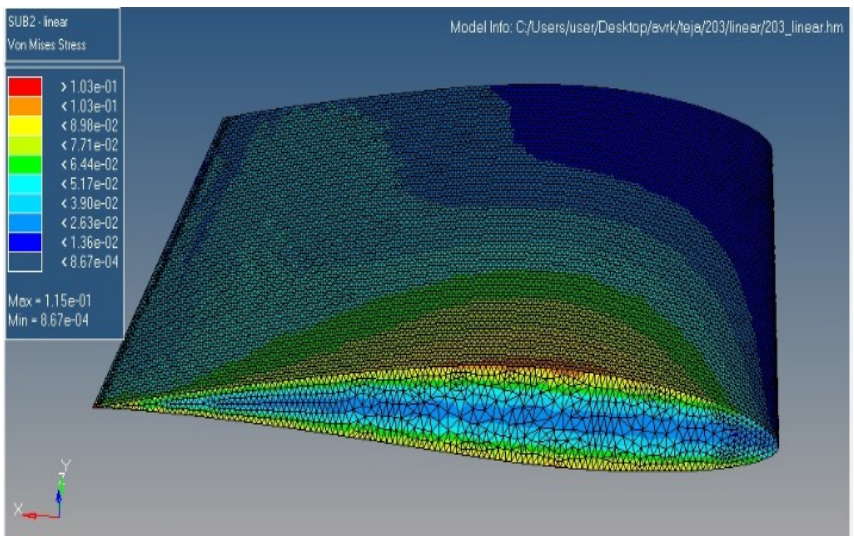

Fig-6: Maximum Stress

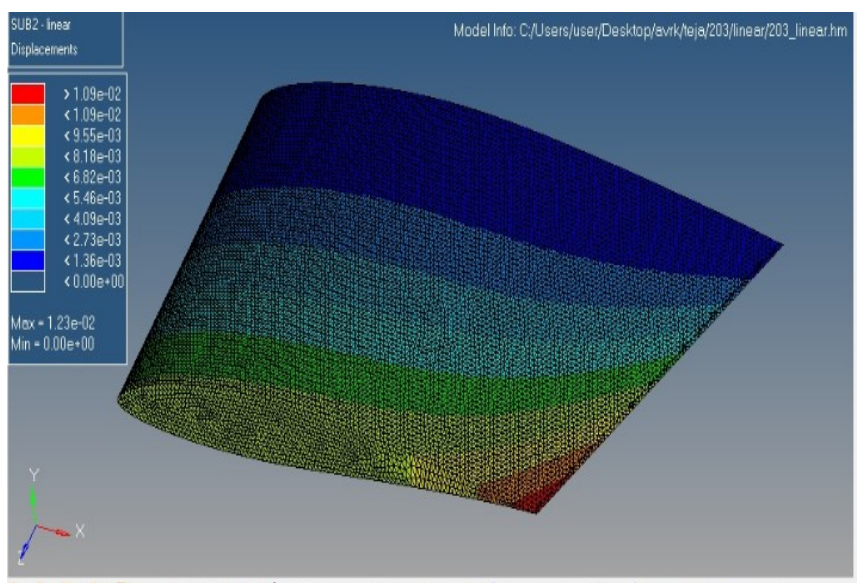

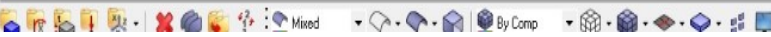
Fig-7: Maximum Displacement

Table-1: Natural Frequencies of E203

\begin{tabular}{|l|l|}
\hline S.no & Frequency \\
\hline 1 & SUB1-F1 $=6.05302 \mathrm{E}+02$ \\
\hline 2 & SUB1-F2 $=1.26551 \mathrm{E}+03$ \\
\hline 3 & SUB1-F3 $=2.40485 \mathrm{E}+03$ \\
\hline 4 & SUB1-F4 $=2.54152 \mathrm{E}+03$ \\
\hline 5 & SUB1-F5 $=2.85621 \mathrm{E}+03$ \\
\hline 6 & SUB1-F6 $=3.24924 \mathrm{E}+03$ \\
\hline 7 & SUB1-F7 $=4.20052 \mathrm{E}+03$ \\
\hline 8 & SUB1-F8 $=4.52728 \mathrm{E}+03$ \\
\hline 9 & SUB1-F9 $=4.99478 \mathrm{E}+03$ \\
\hline 10 & SUB1-F10 $=5.10725 \mathrm{E}+03$ \\
\hline
\end{tabular}


Fig. 8 and Fig.9 shows the maximum stress and maximum displacement of R140 and natural frequencies are presented in Table.2.

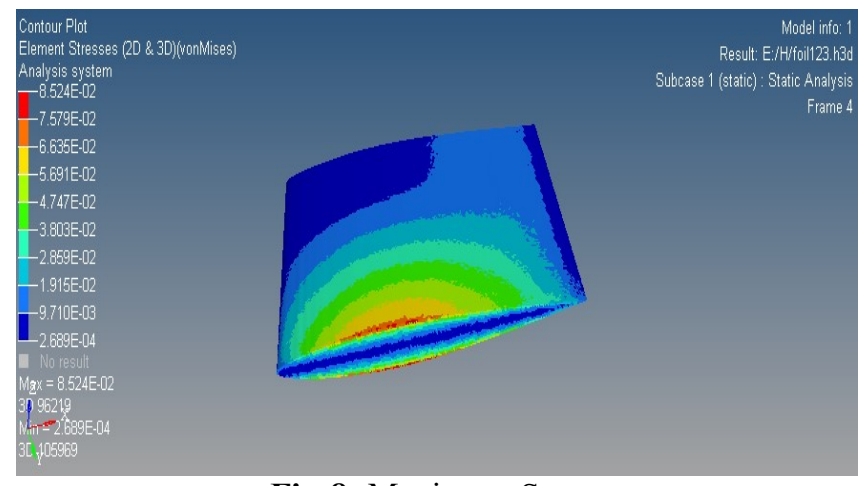

Fig-8: Maximum Stress

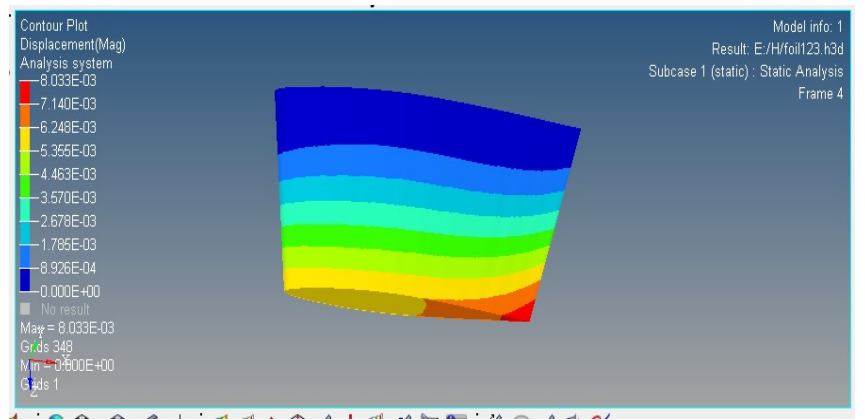

Fig-9: Maximum Displacement

Table-2: Natural Frequencies of R140

\begin{tabular}{|l|l|}
\hline S.no & Frequency \\
\hline 1 & SUB6-F1 $=5.57019 \mathrm{E}+02$ \\
\hline 2 & SUB6-F2 $=1.05592 \mathrm{E}+03$ \\
\hline 3 & SUB6-F3 $=2.16667 \mathrm{E}+03$ \\
\hline 4 & SUB6-F4 $=2.44012 \mathrm{E}+03$ \\
\hline 5 & SUB6-F5 $=2.85378 \mathrm{E}+03$ \\
\hline 6 & SUB6-F6 $=2.89090 \mathrm{E}+03$ \\
\hline 7 & SUB6-F7 $=3.89946 \mathrm{E}+03$ \\
\hline 8 & SUB6-F8 $=4.39612 \mathrm{E}+03$ \\
\hline 9 & SUB6-F9 $=4.86644 \mathrm{E}+03$ \\
\hline 10 & SUB6-F10 $=5.05874 \mathrm{E}+03$ \\
\hline
\end{tabular}

\section{CONCLUSIONS}

The aim of the investigation is to optimize the shape of MAV airfoil which hovers at a height of $100 \mathrm{~m}$. Based on Reynolds Number, parameters are selected for analysis to suggest an optimum airfoil. From the results it can be concluded that E203 airfoil is efficient than R140 under stipulated operating conditions.

\section{REFERENCES}

[1]. Rahul Balki, Akash Thakur, Sagar Sakhrekar, and Manish Wankhede, "Micro-Air Vehicle for Surveillance". International Conference on Advances in Engineering \& Technology-2014 (ICAET-2014) page no.53.

[2]. Mostafa Hassanalian, Mahmud Ashrafizaadeh, Saeed Ziaei-Rad, Mohmmad Reza Radmanesh, "A new method for design of fixed wing Micro Air Vehicle", page no.1.

[3]. Gabriel E .Torres and Thomas J .Mueller, Low aspect ratio wing aerodynamics at low Reynolds numbers, University of Notre Dame, Notre Dame, Indiana 46556,AIAA JOURNAL MAY 2004.

[4]. Thomas J .Mueller, and James C, Kellogg. "Introduction to the Design of Fixed-Wing Micro Air Vehicle”.2006.

\section{BIOGRAPHIES}

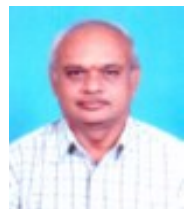

K.V.Ramana. Obtained his $\mathrm{PhD}$ from Andhra University. Guided Seven Doctoral Thesis and published 50 papers. Completed four funded projects. Till date, has put in 34 years of teaching and research experience.

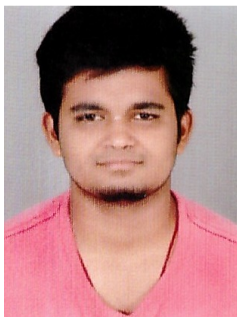

N.S.K.Teja

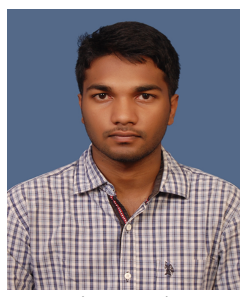

J.Sri Harsha

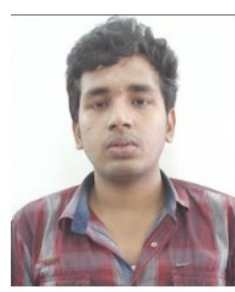

AVRK Teja

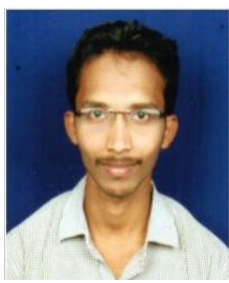

S.Ganesh 